\title{
Bibliometric analysis of articles published in Anatomy, the official publication of the Turkish Society of Anatomy and Clinical Anatomy between 2007-2018
}

\author{
Saliha Seda Adanır (D), İlhan Bahşi (D), Piraye Kervancıŏ̆lu (D), Mustafa Orhan (D), Ömer Faruk Cihan (iD \\ Department of Anatomy, School of Medicine, Gaziantep University, Gaziantep, Turkey
}

\begin{abstract}
Objectives: Bibliometry is a research approach to measure and analyze the productivity of the literature in a specific area or journal. Therefore, bibliometric analysis is significant in the evaluation of the journals. In this study, we aimed to examine the articles published in Anatomy (ISSN: 1307-8798), the official publication of the Turkish Society of Anatomy and Clinical Anatomy (TSACA) between 2007-2018.

Methods: The affiliations of the authors, identity, type, content and number of citations of articles published in the journal Anatomy between 2007-2018 were recorded. Descriptive statistics of the data were made.

Results: Between 2007 and 2018, 214 articles were published in 12 volumes and 19 issues, the number of published articles varying by years. $101(47.6 \%)$ of 214 articles were cited. Forty four articles (20.56\%) were prepared by a single author, and 170 (79.44\%) articles by multiple authors.
\end{abstract}

Conclusion: The findings obtained in this study are thought to be important for understanding the place of the journal Anatomy and its contribution to the scientific literature in the field of anatomy.

Keywords: anatomy; article; bibliometric analysis; citation

Anatomy 2020;14(1):39-43 @2020 Turkish Society of Anatomy and Clinical Anatomy (TSACA)

\section{Introduction}

The journal of Anatomy (ISSN: 1307-8798), the official publication of the Turkish Society of Anatomy and Clinical Anatomy (TSACA), is an international refereed journal published three times a year. In the journal, anatomical studies including histological, developmental, neurological, radiological, clinical and anatomy teaching methods and techniques are published. The journal, the first issue of which was published in 2007, is indexed and abstracted in TUBITAK ULAKBIM TR Index, Index Copernicus, Proquest, EBSCO Academic Search Complete and Google Scholar. ${ }^{[1]}$ On the other hand, Anatomy is one of the 18 official journals in the Federative International Committee for Scientific Publications (FICSP) of International Federation of Associations of Anatomists (IFAA) ${ }^{[2]}$
Bibliometry ( $\beta_{1} \beta_{1} \lambda_{1} 10:$ book, $\mu \varepsilon \tau \rho \eta \sigma \eta:$ measurement $)$ is a Greek origin word, and entered the literature for the first time in 1969 by Alan Pritchard (1935-2010) with his work titled Statistical Bibliography or Bibliometrics. But it became popular in the 1980s. ${ }^{[3,4]}$ Bibliometry is defined as a kind of research approach used to measure and analyze the productivity of the literature in a specific area or journal. ${ }^{[5-7]}$ Bibliometric analyses include the characteristics of published articles, citations, and the number of authors. ${ }^{[8]}$ Therefore, it is an important method to evaluate the scientific features of a journal. It also provides information for understanding scientific productivity and researchers' publication preferences. ${ }^{[6,7]}$ Many disciplines use bibliometric analysis to determine the impact of their field, the impact of a number of researchers, or the impact of a spe-

This study was presented as an oral presentation at 8th Anatomy Winter Meeting, 22-24 fanuary 2020, Trabzon, Turkey. 
cific article ${ }^{[6]}$ Scientific journals are considered as the most up-to-date tool of scientific communication..$^{[9]}$ For this reason, it is considered important to evaluate the journals as bibliometric.

Although there are many studies ${ }^{[4-15]}$ using bibliometric method in different areas, it has been seen in the detailed literature review that the number of bibliometric studies in the field of anatomy is very few. ${ }^{[1,17]}$ In this study, we aimed to examine the articles published in Anatomy (ISSN: 1307-8798), the official publication of the Turkish Society of Anatomy and Clinical Anatomy (TSACA) between 2007-2018, bibliometrically.

\section{Materials and Methods}

All articles published in the Anatomy (ISSN: 1307-8798) between 2007 and 2018 were reviewed on the journal's website. The full text of the articles in all issues, excluding the special issues published between these years, was evaluated and the name of each article, the year it published, the volume, issue and page numbers, the authors, the institutions to which the authors were affiliated, the type of the article and the study design were recorded. On 29 November 2019, each article was accessed from the Google Scholar database and the number of citations was recorded.

\section{Statistical Analysis}

Descriptive statistics are given as mean \pm standard deviation for numerical variables and number and percentage values for categorical variables. SPSS for Windows version 22.0 (SPSS Inc., Chicago, IL, USA) package software was used for statistical analysis and $\mathrm{p}<0.05$ was considered statistically significant.

\section{Results}

Twelve volumes, 19 issues and 214 articles were published in Anatomy between 2007-2018 (Table 1). The number of published articles varied by years and the highest number of peer-reviewed articles were published in 2016. The categories of published articles are shown in Table 2. The majority of published articles were original articles (45.3\%). The study design of original articles and case reports are shown in Table 3 . The vast majority of original articles were experimental animal (29.9\%) and radiological $(22.7 \%)$ studies. $65.2 \%$ of case reports were cadaveric studies.

Fourty-four (20.56\%) of 214 articles were found to be single author, and 170 (79.44\%) articles were found to be more than one author. There were 190 articles with authors from the same country and 24 articles with authors
Table 1

Distribution of published articles by years.

\begin{tabular}{lccc} 
Year & Volume number & Issue number & Niumber of articles \\
\hline 2007 & 1 & 1 & 1 \\
\hline 2008 & 2 & 1 & 14 \\
\hline 2009 & 3 & 1 & 15 \\
\hline 2010 & 4 & 1 & 9 \\
\hline 2011 & 5 & 1 & 8 \\
\hline 2013 & 7 & 1 & 16 \\
\hline 2014 & 8 & 1 & 12 \\
\hline 2015 & 9 & 1 & 11 \\
\cline { 2 - 4 } & & 2 & 14 \\
\hline 2016 & 10 & 3 & 14 \\
\cline { 2 - 4 } & & 1 & 15 \\
\hline 2017 & 11 & 2 & 13 \\
& & 3 & 12 \\
\hline 2018 & 12 & 1 & 9 \\
\hline & & 2 & 9 \\
\hline Total & & 3 & 11 \\
\hline
\end{tabular}

from more than one country. One hundred ten (57.89\%) articles of 190 were from Turkey, followed by Nigeria (7.36\%), India (5.78\%) and USA (4.68\%). Thirty three different countries made contributions to the journal.

When the citations to the articles were analyzed, 101 $(47.6 \%)$ of 214 articles were cited (Figures 1 and 2). The most cited article with 44 citations was an original article and a clinical study. The total number of citations

Table 2

Article types and citations by article types.

\begin{tabular}{lcc} 
Article type & $\mathbf{n}(\%)$ & Citation $($ Mean \pm SD) \\
\hline Original article & $97(45.3)$ & $2.97 \pm 6.41$ \\
\hline Case report & $46(21.5)$ & $3.43 \pm 5.47$ \\
\hline Teaching anatomy & $20(9.3)$ & $4.5 \pm 9.44$ \\
\hline Review & $15(7)$ & $2.46 \pm 3.39$ \\
\hline Book review & $10(4.7)$ & - \\
\hline Editorial & $6(2.8)$ & - \\
\hline Historical view & $6(2.8)$ & - \\
\hline Obituary & $4(1.9)$ & - \\
\hline Terminology zone & $4(1.9)$ & $-25 \pm 0.5$ \\
\hline Viewpoint & $2(0.9)$ & - \\
\hline Letter to the editor & $2(0.9)$ & - \\
\hline Announcement & $1(0.5)$ & $13^{*}$ \\
\hline Invited review & $1(0.5)$ & \\
\hline
\end{tabular}

${ }^{*}$ It was determined that there is only one article invited review and it has 13 citations. $\mathrm{n}$ : total number of articles; SD: standard deviation. 
to the articles in the journal was 588 and the average value was $2.74 \pm 5.97$. The highest number of citations was 97 and in 2016 (Figure 1). In addition, it has been observed that the number of citations to articles published in 2008 is more than the other years (Figure 2).

When the citation numbers were examined according to article types, the highest number of citations was 13 for the invited articles. In other article types, the article type with the highest citation average was teaching anatomy (Table 2). When the original articles were evaluated according to the study design, it was found that the clinical and cadaveric studies had the highest citation average. Similarly, in case reports, it was determined that the studies with the highest citation average were cadaveric studies.

\section{Discussion}

Bibliometric studies are important in evaluating the development and productivity of a scientific area or journal in the literature. In addition, bibliometric researches provide an idea about the future vision of a journal. Although there are studies using bibliometric method in various fields in the literature, there are very few bibliometric studies in the field of anatomy, ${ }^{[1,1,17]}$ and there are no bibliometric studies on anatomy journals.

Citation analysis is the most commonly used form of bibliometry, allowing to measure the impact factor of journals. ${ }^{[8]}$ Petekkaya ${ }^{[16]}$ examined the 100 most cited articles in
Table 3

Distribution of original article and case report articles by study design.

\begin{tabular}{lcc} 
Study design & Original article & Case report \\
\hline Experimental animal study & $29(29.9 \%)$ & - \\
\hline Radiologic study & $22(22.7 \%)$ & $10(21.7 \%)$ \\
\hline Clinical study & $13(13.4 \%)$ & $2(4.3 \%)$ \\
\hline Cadaveric study & $12(12.4 \%)$ & $30(65.2 \%)$ \\
\hline Dry bone study & $8(8.2 \%)$ & $3(6.5 \%)$ \\
\hline Histologic study & $4(4.1 \%)$ & - \\
\hline Fetus study & $4(4.1 \%)$ & - \\
\hline Dry bone and radiologic study & $3(3.1 \%)$ & - \\
\hline Cadaveric and radiologic study & $1(1 \%)$ & - \\
\hline Autopsy study & - & $1(2.2 \%)$ \\
\hline Other & $1(1 \%)$ & - \\
\hline
\end{tabular}

the field of anatomy from the Web of Science database and found that the average citation for the articles was 634.83 accordingly. Also, it was stated that the most cited article had 4471 citations. ${ }^{[16]}$ Wing and Massoud ${ }^{[17]}$ examined the neuroimaging studies conducted in the field of anatomy in two different neuroradiology journals, and determined that there were 244,119 articles and 6419 citations to these articles between 1970-2009. It has been reported that the probability of citing articles decreases in a certain time after publication of the article. ${ }^{[18]}$ In the present study, the total number of citations to articles com-

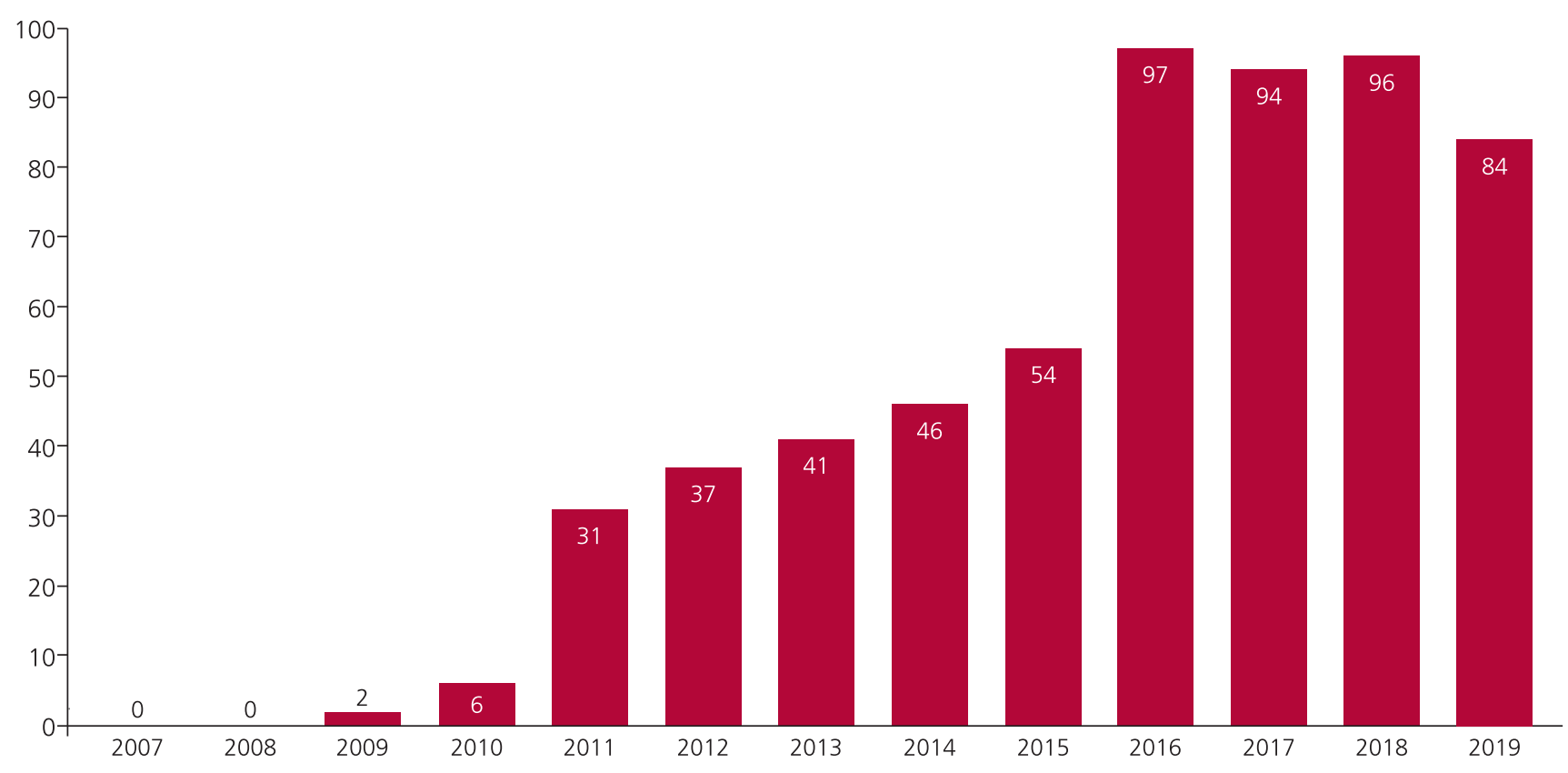

Figure 1. The number of citations to Anatomy varies by the years. 


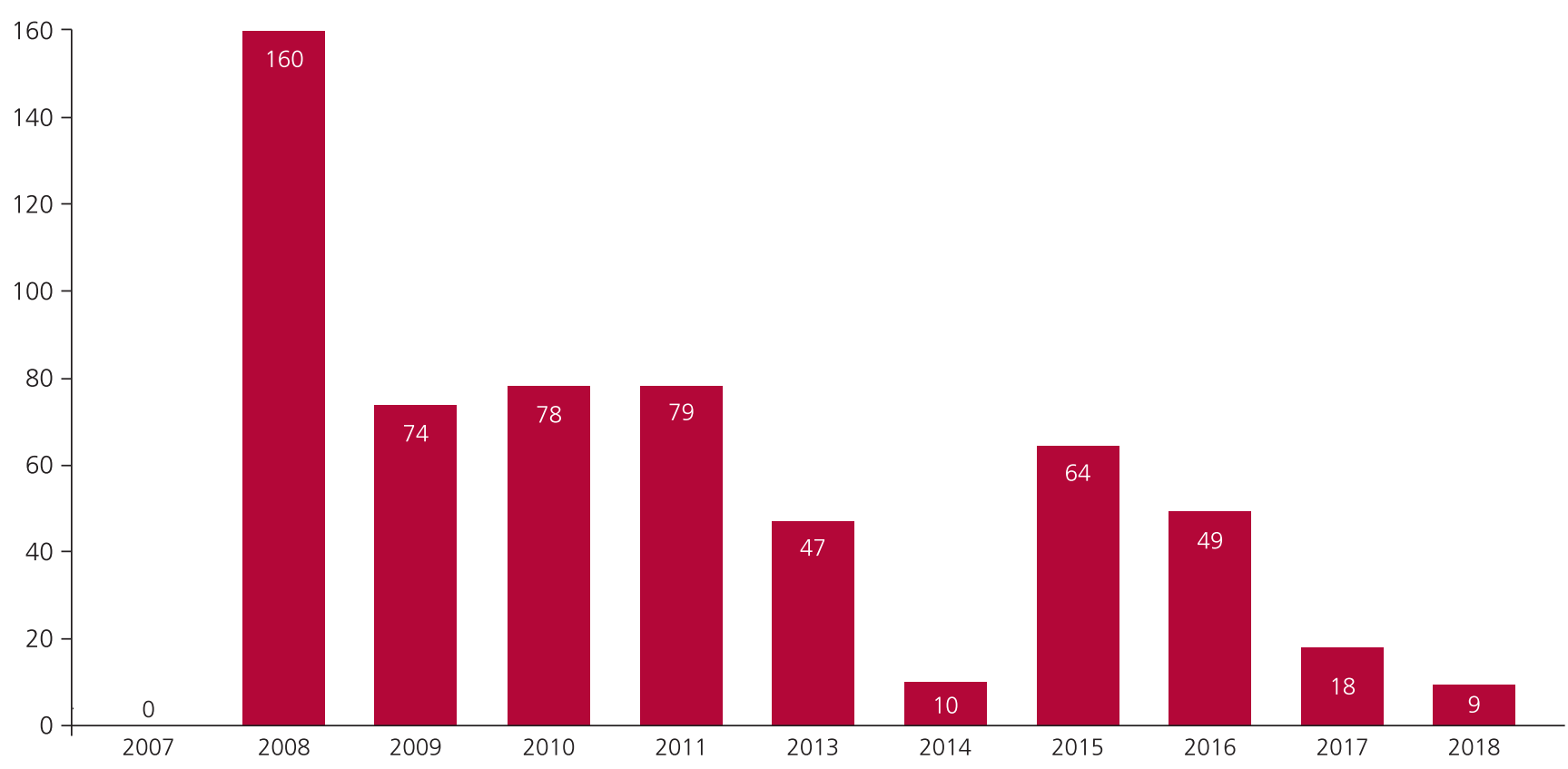

Figure 2. The number of citations and year of publication of articles in the journal Anatomy.

pared to the years they were published was close to each other, but the total number of citations to articles published in 2008 was higher than other years, possibly because the most cited article was published in 2008 .

Weale et al. ${ }^{[19]}$ reported that the number of citations varied according to the article type and study design in the study which they evaluated the citation analysis of all original articles and reviews in the field of immunology in the Web of Science database. Similarly, in the present study, the number of citations to articles in Anatomy varied according to years, article type and study design. The fact that the number of citations of clinical and cadaveric studies is higher than others suggest that the interest in the studies in this field and the publication rate of the studies is higher than the others.

Another factor that affects the number of citations is the open access policy of the journals. Eysenbach ${ }^{[20]}$ reported that the citation average of the articles with open access published in the same journal is significantly higher than those without open access. The acceptance of open access policy of Anatomy can be seen as an advantage in terms of the number of citations to published articles in Anatomy. On the other hand, despite the fact that all articles are open access, the journal does not demand any fees from the authors during the article evaluation or acceptance stage, and this is an indication that they are selective about the articles accepted in the journal.
Yang et al. ${ }^{[21]}$ reported that many researchers needed collaboration in medical publications. Ullah et al. ${ }^{[5]}$ found that there was more than one author in $91.21 \%$ of the articles in a medical journal they examined bibliometrically. In another study conducted by Ullah et al., ${ }^{[22]}$ the rate of single author articles was found to be $4.64 \%$. In this study, more than one author was found in $79.43 \%$ of the articles. The high number of articles with more than one author suggests that co-authorship is important in the emergence of publications in the field of medicine.

Nasir et al. ${ }^{[14]}$ reported that international cooperation is important for the emergence of quality publications. In 24 $(11.2 \%)$ of 214 articles evaluated in the present study, it was determined that there were authors from more than one country. In these articles, it is seen that authors from Turkey are mainly working with authors from countries such as USA, Switzerland, and Germany.

In the study that examined the Journal of Pakistan Medical Association as bibliometrics, it is found $78 \%$ of the articles are from the same country (Pakistan), followedby Iran and Turkey. ${ }^{[23]}$ Similarly, in the present study, the maximum contribution to the Anatomy was made by the authors from Turkey. On the other hand, the contribution of the journal from 33 different countries is an indication that the journal is also respected internationally.

The increase in the number of issues and articles published in Anatomy every year since 2007 shows that the 
journal has a tendency to grow. The majority of the published articleas type are original articles. This is also important for the future demanding of the journal. On the other hand, the fact that the journal's most cited article type is on anatomy education (Teaching Anatomy) shows that the contribution of such articles to the journal is remarkable.

\section{Conclusion}

Examining scientific journals bibliometrically provides understanding of the place of journals in the literature and having an idea about its future vision. The findings obtained in this study are important for understanding the place of Anatomy in the literature and its contribution to the literature.

\section{Author Contributions}

SSA: data collection, literature review, writing text. İB: literature review, writing text, final check of the manuscript. PK: writing text, final check of the manuscript, MO: writing text, final check of the manuscript, ÖFC: writing text, final check of the manuscript.

\section{References}

1. Anatomy journal official website. [Internet]. [Retrieved on December 12, 2019]. Available from: https://dergipark.org.tr/tr/pub/anatomy.

2. IFAA official website. [Internet]. [Retrieved on February 24, 2020]. Available from: www.ifaa.net/committees/scientific-publicationsficsp/

3. Pritchard A. Statistical bibliography or bibliometrics. Journal of Documentation 1969;25:348-9.

4. Dhiman A. Ethnobotany Journal: a ten year bibliometric study. IASLIC Bulletin 2000;45:177-82.

5. Ullah M, Butt IF, Haroon M. The Journal of Ayub Medical College: a 10-year bibliometric study. Health Info Libr J 2008;25:116-24.

6. Abdi A, Idris N, Alguliyev RM, Aliguliyev RM. Bibliometric analysis of IP\&M Journal. Journal of Scientometric Research 2018;7:54-62.

7. Roy SB, Basak M. Journal of Documentation: a bibliometric study. Library Philosophy and Practice (e-journal) 2013:945.

ORCID ID:

S. S. Adanır 0000-0002-9098-5194; I. Bahşi 0000-0001-8078-7074; P. Kervancıoğlu 0000-0003-3231-3637; M. Orhan 0000-0003-4403-5718;

Ö. F. Cihan 0000-0001-5290-4384
8. Coronado RA, Wurtzel WA, Simon CB, Riddle DL, George SZ. Content and bibliometric analysis of articles published in the Journal of Orthopaedic \& Sports Physical Therapy. J Orthop Sports Phys Ther 2011;41:920-31.

9. Ahmed I, Ullah M. A 10-year bibliometric study of Pakistan Journal of Pharmaceutical Sciences. Library Philosophy and Practice (ejournal) 2018;2128.

10. Hu J, Ma Y, Zhang L, Gan F, Ho YS. A historical review and bibliometric analysis of research on lead in drinking water field from 1991 to 2007. Sci Total Environ 2010;408:1738-44.

11. Chuang KY, Chuang YC, Ho M, Ho YS. Bibliometric analysis of public health research in Africa: the overall trend and regional comparisons. South African Journal of Science 2011;107:54-9.

12. Maharana RK, Sethi BB. A bibliometric analysis of the research output of Sambalpur University's publication in ISI Web of Science during 2007-11. Library Philosophy and Practice 2013;15.

13. Kumar M. Library Herald journal: a bibliometric study. Journal of Education \& Social Policy 2014;1:123-34.

14. Nasir S, Ahmed J, Asrar M, Gilani AH. A bibliometric analysis of pharmacy/pharmacology research in Pakistan. International Journal of Pharmacology. 2015;11:766-72.

15. Thompson DF. Bibliometric analysis of pharmacology publications in the united states: a state-level evaluation. Journal of Scientometric Research 2018;7:167-72.

16. Petekkaya E. The most cited articles in anatomy: an update study. Biomedical Journal of Scientific \& Technical Research 2019;22: 16486-94.

17. Wing L, Massoud TF. Trends in performance indicators of neuroimaging anatomy research publications: a bibliometric study of major neuroradiology journal output over four decades based on Web of Science database. Clin Anat 2015;28:16-26.

18. Redner $S$. How popular is your paper? An empirical study of the citation distribution. Eur Phys J B 1998;4:131-4.

19. Weale AR, Bailey M, Lear PA. The level of non-citation of articles within a journal as a measure of quality: a comparison to the impact factor. BMC Med Res Methodol 2004;4:14.

20. Eysenbach G. Citation advantage of open access articles. PLoS Biol 2006; 4:e157.

21. Yang H, Pan B-C, Chen J. Citation analysis of five journals in andrology. Arch Androl 2006;52:433-40.

22. Ullah S, Ahmad HN, Jan SU, Jan T, Shah S, Butt NI, Yan MY. A statistical analysis of Pakistan Journal of Surgery: a bibliometric lens from 2007-2016. Pakistan Journal of Surgery 2017;33:123-7.

23. Ibrahim M, Jan SU. Bibliometric analysis of the Journal of Pakistan Medical Association form 2009 to 2013. J Pak Med Assoc 2015;65: 978-83.

Correspondence to: Ihan Bahși, MD, PhD Department of Anatomy, School of Medicine, Gaziantep University, Gaziantep, Turkey

Phone: +90 34236060 60/4655

e-mail: dr.ilhanbahsi@gmail.com

Conflict of interest statement: No conflicts declared.

This is an open access article distributed under the terms of the Creative Commons Attribution-NonCommercial-NoDerivs 3.0 Unported (CC BY-NCND3.0) Licence (http://creativecommons.org/licenses/by-nc-nd/3.0/) which permits unrestricted noncommercial use, distribution, and reproduction in any medium, provided the original work is properly cited. Please cite this article as: Adanır SS, Bahşi İ, Kervancıŏlu P, Orhan M, Cihan ÖF. Bibliometric analysis of articles published in Anatomy, the official publication of the Turkish Society of Anatomy and Clinical Anatomy between 2007-2018. Anatomy 2020;14(1):39-43. 